\title{
Brussels seeks tighter control over European funds for Russian science
}

London. The European Commission in Brussels appears to be on a collision course with some European Union (EU) states over the way in which it provides financial support for scientists in Russia and other states of the former Soviet Union (FSU).

Edith Cresson, the former French socialist prime minister who took over as the EU's commissioner of research at the beginning of this year, wants the ECU250 million (US\$325 million) allocated partly for this purpose within the commission's Fourth Framework research programme to be more focused on areas of research likely to benefit the economies of FSU states.

Cresson is also keen that work currently being undertaken by INTAS, the international body set up in June 1993 to administer such aid with funds from the EU and other European states, should be taken on by the commission itself. INTAS has come under strong criticism for its slowness in getting individual projects off the ground.

The commissioner's proposals will be put to EU research ministers who meet next week. At their last meeting, the ministers agreed, at Cresson's suggestion, to postpone a decision restricting their contribution to INTAS until the situation was reassessed.

But Cresson's proposals are likely to

meet fierce opposition at the ministerial meeting from those who argue that INTAS's record has been improving in recent months, and that it should now be given the chance to prove itself. Some government officials say that, whatever criticism has been made of the bureaucratic procedures followed by INTAS, these are unlikely to be reduced by transferring the administration of funds to the commission.

There is also concern that the commission's proposal to keep direct control of the allocation of funds to scientists in Russia

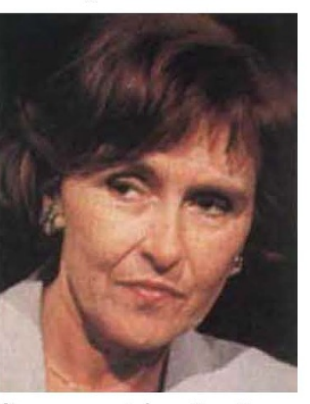

Cresson: claims funds have been mismanaged. and other FSU states may be part of a strategy to enhance its position in Brussels, a tendency which they view with suspicion.

In a statement published last week, Cresson says that the EU's support for FSU scientists should concentrate on priority topics such as environmental protection, nuclear safety, and space technology. She also says that selection criteria should be tightened,

\section{Nature heads ISI citations survey}

\begin{abstract}
London. A survey of citations to papers published in three leading science journals has revealed that papers in Nature are referred to more frequently than those in its two main rivals in all major fields of research.
\end{abstract}

During the period 1981-1994, Nature had a greater citation impact more citations per paper - than either Science or the Proceedings of the National Academy of Sciences (PNAS), according to data published in the June issue of Science Watch, published by the Institute for Scientific Information.

The survey covered seven subject areas in the physical and biological sciences in a series of five-year blocks. Nature's impact in the biological sciences rose from just under 30 citations per paper between 1981 and 1985, to about 60 between 1991 and 1994. Biological citations from Science rose from 20 to 50 per paper for the same period.

In the physical sciences, the two journals were neck-and-neck for most of the 1980s. But while Nature's citations continued to rise - from seven per paper in 1981-85 to about 19 by 1991-94 - Science has been steady at about 15 since 1988. Citations from PNAS, though consistent throughout, were much lower than the other two, at 20 in the biological sciences and less then 10 for the physical sciences.

Detailed breakdowns revealed immunology to be Nature's most-likely cited field with over 90 citations per paper. (Science had 70 citations.) In molecular biology, Nature's citations-perpaper score rose sharply through the early 1980 s, but fell off in the latter part of the decade, to be surpassed by Science. But Nature re-established its preeminent position in the late 1980 s.

In chemistry, Nature's impact scores substantially lagged behind those of Science for much of the 1980s. But its citations have risen steeply since then, and now stand at just under 30 per paper. "Carbon chemistry, and, particularly, papers on $\mathrm{C}_{60}$ and the other fullerenes helped lift Nature's impact in this field," the survey reports.

Ehsan Masood with preference given to projects that are "closer to industrial exploitation", and candidates being required to demonstrate the potential utility of their research.

Cresson also said that it would be "more appropriate" to integrate the activities of INTAS financed by the EU within the administration of the Framework programme, and that the commission should not continue to participate in INTAS itself after the end of this year.

Jean-Christophe Filori, a spokesman for Cresson, claims that an independent audit had been unable to show that INTAS was any more efficient than the commission itself, and also revealed evidence of 'mismanagement' - such as funds being allocated to projects before all the paperwork had been completed. "We think that INTAS has been a great idea, but it is too expensive and not effective enough," Filori says.

Even supporters of INTAS acknowledge that its procedures, partly made necessary by the need to respect both the Belgium legislation under which it was set up and Russian regulations on external grants, have left many scientists frustrated at delays in getting funds to Soviet colleagues.

"This experiment has been delayed by a number of factors, which can be corrected," says Fritz Stoeckli of the University of Neuchâtel, who is Switzerland's representative on INTAS's Council of Scientists, writing in the current issue of the Soviet journal Poisk. "However this does not excuse the present situation, and we expect that lessons will be drawn for the future."

But, with the money at last beginning to flow, criticism is on the wane. "They are beginning to pull their fingers out," says John Osborne, a physicist at the University of Durham in England, who had been previously experiencing long delays in obtaining promised support for collaborators in Moscow.

Next week's meeting will, therefore, be vital for the future of the organization. Filori says that, even if INTAS were to close down, some of its 30 staff members would be transferred to the commission, and all existing commitments would be met.

But INTAS points out that it has almost eliminated its backlog of grants, and has recently signed an agreement with Russian authorities that should remove some previous obstacles. With Cresson already facing a rebuff over an earlier bid to reserve ECU700 million left unallocated within the Framework budget for industrial projects, the struggle over INTAS could become a test of political will between the commission and EU members.

David Dickson 